\title{
University students' perceptions of pre-school and kindergarten children who stutter
}

\author{
Ilana Roth Betz ${ }^{\mathrm{a}}$, Gordon W. Blood ${ }^{\mathrm{b}, *}$, Ingrid M. Blood ${ }^{\mathrm{b}}$

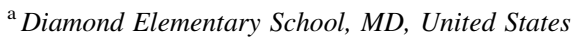 \\ ${ }^{\mathrm{b}}$ Department of Communication Sciences and Disorders, 308 Ford Building, \\ The Pennsylvania State University, University Park, PA 16802, United States
}

Received 4 May 2007; received in revised form 26 July 2007; accepted 22 October 2007

\begin{abstract}
To determine how early "the stuttering stereotype" is assigned, 160 university students rated a hypothetical vignette depicting either a 3-, 4-, 5-, or 6-year-old with or without the statement "He stutters". A factor analysis of the semantic differential scale showed a three-factor solution comprised of 17 of the 25 bi-polar adjective pairs. The factor labeled personality showed significantly more negative ratings for 2-, 4-, 5-, or 6-year-old children based on the inclusion of the "He stutters" sentence. There were no differences between male and female raters. A significant difference was found between raters who were knew someone who stuttered and raters who did not know someone who stuttered on the personality factor. Raters who were knew someone who stuttered were significantly more likely to assign more positive ratings to the children.
\end{abstract}

Learning outcomes: Readers should be able to learn and understand: (1) the research describing the negative stereotypes associated with stuttering; (2) the vignette method used to evaluate stereotypes in children and youth; (3) the negative perceptions of the sentence "He stutters" on raters' perception of personality, sociability and speech for children as young as 3-, 4-, 5-, or 6 -year-olds; and (4) the familiarity with a person who stutters and raters' perceptions of children who stutter.

(C) 2007 Elsevier Inc. All rights reserved.

* Corresponding author.

E-mail address: f2x@psu.edu (G.W. Blood). 


\section{Introduction}

For more than 4 decades, researchers have reported on the negative perceptions and attitudes toward individuals who stutter. As early as the 1970s, authors were sharing their research findings on the negative perceptions of boys and men who stuttered (Woods \& Williams, 1971, 1976; Yairi \& Williams, 1970). Since that time, dozens of studies have confirmed the original hypotheses that educators, administrators, speech language pathologists (SLPs), employers, peers, medical personnel, family members, and university students perceive persons who stutter (PWS) as more negative simply because of the presence of a communication disability (Bebout \& Bradford, 1992; Corcoran \& Stewart, 1998; Crowe \& Cooper, 1977; Crowe \& Walton, 1981;Dorsey \& Guenther, 2000; Ham, 1990; Kalinowski, Armson, Stuart, \& Lerman, 1993; Lass et al., 1994; Turnbaugh, Guitar, \& Hoffman, 1979; Woods \& Williams, 1971). PWS are stereotyped as more insecure, withdrawn, introverted, fearful, anxious, tense, nonassertive, and more afraid to talk than people who do not stutter. This pervasive negative stereotype has implications for assessment, treatment, and quality of life for PWS. Daniels and Gabel (2004) noted that PWS have difficulty constructing a positive identity, in part because of their social interactions with others who uphold the stuttering stereotype.

Bloodstein (1995), Guitar (2005), Shapiro (1999), Sheehan (1970), Van Riper (1982) and others suggest that negative stereotypes and prejudices toward PWS may be formed early in childhood. Researchers suggest that an integration of these negative stereotypes in the social identity of the PWS may contribute to the "stigma" of stuttering (Blood, Blood, Tellis, \& Gabel, 2001; Daniels \& Gabel, 2004; Van Borsel, Verniers, \& Bouvry, 1999; Whaley \& Parker, 2000; Yovetich, Leschied, \& Flicht, 2000). Other researchers report PWS are exposed to job discrimination (Hurst \& Cooper, 1983; Klein \& Hood, 2004; Rice \& Kroll, 1997) and also suffer role entrapment in the form of vocational stereotyping (Gabel, Blood, Tellis, \& Althouse, 2004). Their data suggested that negative stereotypes, low expectations and negative attitudes toward PWS may have deleterious educational, social, and vocational impact. The question of when these negative stereotypes or attitudes develop in both PWS and their conversation partners is still uncertain.

Early intervention has become the backbone of services provided by SLPs. Facilitation and enhancement of language, speech and fluency skills can be achieved at very early ages. According to Becker, Place, Tenzer, and Frueh (1991) once a negative stigma is placed on a child, he or she is less likely to receive the services he needs in order to cope with and/or rectify his difficulty, placing him at an academic and social disadvantage when compared to his peers. Young children who stutter (CWS) are often identified with the negative stigma associated with their speech difficulties. Davis, Howell, and Cooke (2002) examined peer stereotyping of CWS and their non-stuttering classmates. Four hundred and three children, ranging from 8 to 14 years of age, were participants in the study. All participants had a classmate who stuttered and asked to select the three children they liked the most and three children they liked the least. The participants were then asked to choose three children from the class who best fit each of the eight behavioral descriptions: "shy, assertive, cooperative, disruptive, leader, uncertain, bully, and bully victim." They reported 
that fluent participants classified their disfluent classmates with lower social positions. A higher proportion of CWS were in the lower social status group when compared with children who do not stutter. The results of this study are significant because they provide further evidence that stereotypes in PWS may begin at young ages. Eight-year-old children in this study were stereotyping their disfluent classmates with characteristics typically assigned to adults who stutter. If CWS are not only viewed negatively by people who care for them but also classmates, the stuttering stereotype may be perpetuated in social situations with adults as well as peers.

The importance of examining the stuttering stereotype for enhancing our knowledge about assessment, treatment and quality of life for CWS and PWS is evident. We are interested in studying whether the next generation of caregivers who raise, teach, and aid children with communication disabilities are forming negative impressions of CWS. University students provide an interesting pool of participants because they are exposed to increased knowledge bases about disabilities, sensitivity training, exposure to persons with disabilities, and educational campaigns. If these students develop or maintain negative stereotypes of PWS, then renewed or different efforts at earlier ages may be appropriate to dispel stereotypical beliefs. A gap exists in the literature which links university students' perceptions of young children who stutter (CWS) to their knowledge of stuttering and their familiarity of stuttering. There is also a lack of evidence to identify the earliest age at which CWS become labeled with the negative stuttering stereotype by this next generation of parents, educators and care providers. This critical information may not only support the need for early intervention programs with CWS and additional evidence-based support for early fluency facilitation programs (Onslow, 1996, 2003), but also enhanced educational programs for university students.

Specifically this study was designed to answer the following questions:

(1) What are university students' perceptions of pre-school children (3- and 4-year-olds) and school-age children (ages 5 and 6 years) who stutter on a 25 -item adjective rating scale?

(2) Are there significant differences between university students' perceptions of pre-school and school-age children who stutter based on their familiarity with PWS?

\section{Method}

\subsection{Participants}

One hundred and sixty undergraduate students at the Pennsylvania State University completed a survey including items about demographic factors and a bi-polar adjective rating scale. Participants were solicited randomly through fliers distributed around the University campus and provided compensation in the form of a coupon for "free ice cream" at the University for participation in the study. Participants ranged from 18 to 23 years with a mean age of 21.3 years (standard deviation $=2.7$ years). They represented a wide variety of majors including Biology, English, Engineering, Art, Theatre, etc. 
Communication Sciences and Disorders majors were excluded from the study to eliminate potential information bias. One hundred and four students $(65 \%)$ had known people who stutter including relatives, friends, and acquaintances. One hundred and forty-six participants $(91 \%)$ had never had a course in which the topic of stuttering was ever discussed.

\subsection{Survey instrument}

A three-part survey was constructed to assess the respondents' perceptions of CWS and children who do not stutter. Each participant was provided with the first section of the survey consisting of one of eight different paragraphs (Appendix A). The paragraphs were written vignettes identical except for the two variables under study (age and stuttering). This included: age ("Kevin is a 3-, 4-, 5-, or 6-year-old boy") and the presence or absence of the two-word sentence "Kevin stutters." "Kevin stutters" was imbedded in the paragraph or it was completely omitted. It was placed as the sixth sentence of 10 sentences in the vignette. Participants who completed the surveys based on children who did not stutter served as the control group in this study.

Vignette research methodology uses "a short description of a person or a social situation which contain precise reference to what are thought to be the most important factors in the decision-making process or judgment-making processes of respondents" (Alexander \& Becker, 1978, p. 94). The advantages of this methodology have been outlined by numerous researchers including (a) the need to vary only one element to identify specific responses; (b) allows for targeting specific kinds of questions for the researcher; (c) allows for understanding a normative process without intrusive interviews; (d) allows for a depersonalization for the participant from specific personal experiences that might be viewed as threatening; (e) allows for social scientists to study the links between social processes and cognition; and (f) decreases the use of prestructured questions that often contain experimenter bias; (g) allows the participant to define the meaning of the situation or personal characteristic using their own schemata; and (h) can be used in both quantitative and qualitative research studies (Alexander \& Becker, 1978; Finch, 1987; Hughes \& Huby, 2004; Schoenberg \& Ravdal, 2000; Wilson \& While, 1998). The disadvantages include: (a) reduced comparability because the participant is using their own definitions and schemata and (b) the potential that researchers presume that a relationship between responses and actual actions/behaviors at a later date.

Vignette research methodology has been employed in social science research for decades and used in studies children, youth, families and professionals. This methodology has also been used with individuals with communication disorders (Allard and Williams (in press); Lass et al., 1994; Williams \& Dietrich, 1996, 2001; Woods \& Williams, 1971). Clinical vignettes have also proven helpful in predicting variation in the quality of preventive care (Dresselhaus, Peabody, Luck, \& Bertenthal, 2004) and decision-making and professional judgments in social workers, nurses, physicians (Taylor, 2006; Wilson \& While, 1998; Rutten, Harting, Rutten, Bekkering, \& Kremers (2006)). Vignette techniques are reported as valuable research tools for attitude assessment with both children and adults 
(Hasket, Seott, Willoughby, Ahern, \& Nears, 2006; Parker et al., 2001; Van der Pas, van Tilburg, \& Knipscheer, 2005).

The second section of the survey asked respondents to complete a semantic differential scale consisting of 25 items developed by Woods and Williams (1976). The rating of the semantic differential scale was based on the paragraph/vignette they had just completed reading. This scale has been reported in numerous studies examining the stereotype of stuttering. Bi-polar adjectives are randomly placed on the scale with positive and negative pairs being placed on both left and right sides. Each bi-polar adjective pair is presented with a seven-point scale. Anchor points for the scale are the words "very much," "quite a bit," and "slightly" surrounding the word "neutral." Please see Appendix B. The bi-polar adjectives pairs include: guarded-open; nervous-calm; cooperative-uncooperative; shy-bold; friendly-unfriendly; self-conscious-self-assured; tense-relaxed; sensitiveinsensitive; anxious-composed; pleasant-unpleasant; withdrawn-outgoing; quiet-loud; intelligent-dull; talkative-reticent; avoiding-approaching; fearful-fearless; aggressivepassive; afraid-confident; introverted-extroverted; daring-hesitant; secure-insecure; emotional-bland; perfectionist-careless; bragging-self-derogatory; and inflexibleflexible.

Finally, the third section of the survey collected demographic information on participants including: age, year in school, participants' academic major and questions about specific familiarity with stuttering. Questions included:

1. Have you ever taken a class in which stuttering was discussed?

2. Do you know anyone who stutters?If yes, is this person (please circle): a child? an adolescent? an adult?

3. Does this person still stutter?

4. What is your relationship to this person?

\subsection{Procedures}

The three part surveys were given to students in a classroom or office setting. Each participant received the informed consent form at the time of administration of the survey. First, participants were asked to read one of eight short vignettes describing either a 3-, 4-, 5-, or 6-year-old who stuttered or a 3-, 4-, 5- or 6-year-old who did not stutter. Participants were randomly assigned to receive one of the eight scenarios differing only in the stuttering and age variables. Then they were asked to rate their perceptions of the hypothetical child they had just read about by responding to 25 bi-polar adjectives to assess the personal characteristics. Finally, they were asked to complete the familiarity questions outlined above.

\subsection{Data analysis}

Initially the responses on the 25-item bi-polar scale were submitted to a factor analysis to determine the structure of the sample. A series of 2 (group-stuttering and non-stuttering) by 4 (age levels 3-, 4-, 5-, 6-year-olds) ANOVA's using a general linear model and Bonferonni multiple comparison methods based on probability inequalities 
were computed (set at a confidence level of $p<0.05$ ) on the adjective pairs and the factors identified from the factor analysis (G.G. Tabachnick \& Fidell, 2006). A series of one-way ANOVA were computed for the two groups based on familiarity with PWS and bi-polar adjective identified in the factors (B.G. Tabachnick \& Fidell, 2006). All data were submitted for descriptive analysis including means, standard deviations, and ranges.

\section{Results}

\subsection{Factor analyses}

The 25-item adjective scale has been used in numerous investigations with schoolage children, young adults and older adults. However, because the scale has not been used with pre-school children, the 25 items were factor analyzed for this sample of participants to construct a more parsimonious measure. It was possible that participants thought certain adjective pairs were not appropriate or useful for describing pre-school children. Prior to computing the factor analysis, conditions of multicollinearity and singularity among the adjective pairs were determined. Multicollinearity occurs when the items are very highly correlated. Singularity occurs when the items are redundant. Using the communality estimates (squared multiple correlations) analyses revealed the absence of multicollinearity and singularity which is necessary for factor analysis. A factor analyses with oblimin rotation was used because it is recommended if interrelationships exists. Oblimin rotation is an orthogonal rotation. A good rotation method separates variables so that highly correlated variables load a great deal on one factor and less on another factor. An oblimin rotation does not keeps the axes orthogonal or 90 degree apart. The factor structure of the scale was described by Horsley and FitzGibbon (1987) and showed that interrelationships existed. A two-factor solution for a "pre-schooler - no age" and an 8-year-old revealed "Tenseness" and "Pleasantness" scales. Providing participants specific ages down to 3 years and limiting the range may have altered/encouraged different perceptual sets. Selection and retention criteria for factor loadings included minimum eigenvalues greater than 1.0 and factor loadings $\geq .60$. This is recommended as a conservative criterion for factor inclusion (G.G. Tabachnick \& Fidell, 2006).

A principal axis with direct oblimin rotation was conducted on the list of 25 adjective pairs. Three factors were extracted with primary loadings $\geq .60$. Items lower than 0.35 on their factors were deleted from the analyses totaling eight adjective pairs including: anxious-composed; intelligent-dull; fearful-fearless; aggressive-passive; introvertedextroverted; emotional-bland; perfectionist-careless; and inflexible-flexible. This left a new adjective scale with 17 based on three factors. The three factors accounted for $63.6 \%$ of the variance. The three factors were named Personality, Sociability, and Speech, respectively.

Factor 1 is the strongest factor and accounted for $41.6 \%$ of the variance. It describes attributes associated with interpersonal traits and was labeled Personality. Ten bi-polar adjectives pairs loaded on this factor included guarded-open, nervous-calm, shy-bold, 
Table 1

Factor analyses results for the 25-item bi-polar adjective scale

\begin{tabular}{|c|c|c|c|}
\hline Variable & Factor 1 & Factor 2 & Factor 3 \\
\hline Guarded-open & -0.615 & & \\
\hline Nervous-calm & -0.612 & & \\
\hline Shy-bold & -0.656 & & \\
\hline Self-conscious-self-assured & -0.639 & & \\
\hline Tense-relaxed & -0.659 & & \\
\hline Withdrawn-outgoing & -0.692 & & \\
\hline Avoiding-approaching & -0.683 & & \\
\hline Afraid-confident & -0.679 & & \\
\hline Insecure-secure & -0.621 & & \\
\hline Bragging-self-derogatory & -0.611 & & \\
\hline Uncooperative-cooperative & & -0.707 & \\
\hline Friendly-unfriendly & & -0.602 & \\
\hline Insensitive-sensitive & & -0.609 & \\
\hline Pleasant-unpleasant & & -0.628 & \\
\hline Talkative-reticent & & & -0.614 \\
\hline Quiet-loud & & & -0.604 \\
\hline Hesitant-daring & & & -0.633 \\
\hline
\end{tabular}

self-conscious-self-assured, tense-relaxed, withdrawn-outgoing, avoiding-approaching, afraid-confident, secure-insecure, and bragging-self-derogatory. Factor 2 describes attributes of the children, which was labeled Sociability. It accounted for an additional $12.6 \%$ of the variance. Loading on Factor 2 are four bi-polar adjective pairs including: cooperative-uncooperative; friendly-unfriendly; sensitive-insensitive; and pleasantunpleasant. Factor 3 describes the speech of the children (labeled Speech) and accounts for an additional $9.4 \%$ of the total variance. It includes three bi-polar adjective pairs: quietloud, talkative-reticent, and daring-hesitant. Results of the factor analysis are displayed in Table 1.

\subsection{Research question 1}

A condition (inclusion or exclusion of "He stutters") by age level (3-, 4-, 5-, 6-yearold) multivariate analysis of variance and comparison methods based on probability inequalities were computed on the means of the three factors from the 17 adjective pairs (G.G. Tabachnick \& Fidell, 2006). A MANOVA yielded a significant overall effect for condition for Factor 1-Personality $\left(F(1159)=17.53, p<0.001, \eta^{2}=11 \%\right)$ (medium effect size). Post hoc comparisons revealed significant differences for all 10 of the bi-polar adjective pairs in Factor 1 ranging to from 0.005 to 0.001 level of confidence. In contrast, no significant differences were found for the age groups $(F(3159)=0.22, p=0.88)$ or interaction $(F(3159)=0.37, p=0.77)$. It appeared that the specific age range (pre-school versus school-age) had no effect on the participants' ratings. It should be noted that it did not matter if children who stutter were $3,4,5$, or 6 years of age, they were still assigned negative ratings based on the results of the analyses. The stuttering stereotype for personality may have less to do with a specific 


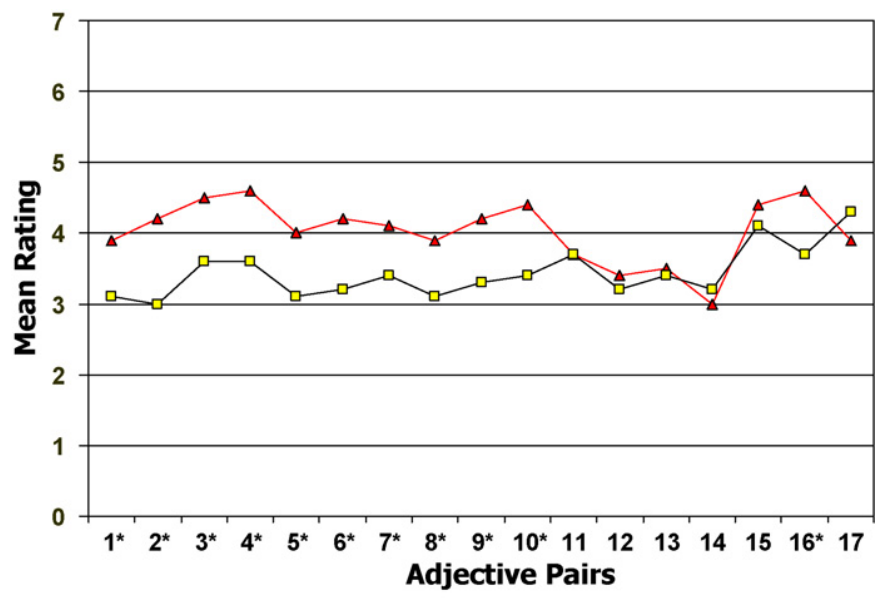

- Children who Stutter $-\square-$ Children who do not Stutter

Fig. 1. Mean ratings of the 3-, 4-, 5-, and 6-year-old children (collapsed across age) for the two conditions ("He stutters" or did not include "He stutters") for the adjective pairs (1) open-guarded*; (2) calm-nervous*; (3) boldshy*; (4) self-assured-self-conscious*; (5) relaxed-tense*; (6) outgoing-withdrawn*; (7) approaching-avoiding*; (8) confident-afraid*; (9) secure-insecure*; (10) bragging-self-derogatory*; (11) cooperative-uncooperative; (12) friendly-unfriendly; (13) sensitive-insensitive; (14) pleasant-unpleasant; (15) talkative-reticent; (16) quiet-loud*; and (17) daring-hesitant. $(*)$ indicates significant differences between conditions.

age and more with the simple association of the label to a child. There was no significant group, age or group- by-age interaction for the four bi-polar adjective word pairs comprising Factor 2 - Sociability. Similarly, there was no significant group, age or group by age interaction for the three bi-polar adjective word pairs comprising Factor 3 - Speech. This suggests that for these specific adjective word pairs, participants were less likely to affix a negative or positive attribute depending on the group or the age of pre-school or school-age children. The bi-polar adjective pair labeled "quiet-loud" revealed a significant difference between means for the two conditions (either including or not including the two-word sentence "He stutters") of 4.6 and 3.7. Fig. 1 displays the means for the two conditions collapsed across age. Children who stutter were rated as significantly more guarded, nervous, shy, selfconscious, tense, withdrawn, avoiding, afraid, insecure, self-derogatory and quiet than children who did not stutter.

\subsection{Research question 2}

Of the 160 students, 104 (65\%) who had known people who stutter including relatives, friends, and acquaintances. Only $14(9 \%)$ of the participants had taken a course that mentioned stuttering. All 14 of these participants also reported they had known people who stutter. All 104 students were placed in the familiarity group, while the remaining 56 (35\%) students who reported they had not known people who stutter or taken a course which mentioned stuttering were placed in the no familiarity group. For these analyses, only the 
80 students who read the vignette with "He stutters" were included. Thirty-three reported they had not known people who stutter, while 47 students reported they had known people who stutter including relatives, friends, and acquaintances. Of those 47 , six of them had also taken a course that mentioned stuttering.

This data was analyzed using three one-way analyses of variance in which the independent variable was the group (familiarity or no familiarity) and the dependent variables were the mean of the 10 adjective pair ratings for Factor 1, the means of the 4 adjective ratings for Factor 2 or the means of the 3 adjective ratings for Factor 3. For Factor 1, the group mean for 47 participants who reported they had known people who stutter was 3.32 (S.D. $=0.8)$ while the group mean for 33 participants who reported they had not known people who stutter was $4.22($ S.D. $=1.2)$. The analysis revealed a significant difference between the groups for Factor $1, F(1,79)=16.62, p<.001$, $d=0.94$ (large effect size). The participants familiar with people who stutter had significantly more positive ratings for children who stutter than participants who were not familiar with people who stutter. No significant differences between the group means were found for Factor $2, F(1,79)=0.22, p=0.65$, or Factor $3, F(1,79)=0.96$, $p=0.33$ for familiarity.

\section{Discussion}

Stereotypes are part of the social environment and influence the expectations and principles of both individuals who hold those stereotypical views and individuals experiencing the stereotype. The results of the analyses showed that university students assign significantly more negative ratings to the hypothetical construct of a child as young as 3 years of age based on the two-word sentence "He stutters." It appears that the mere label "stutter" negatively influenced participants' ratings. These data support earlier studies in the literature that the label "stutter" carries negative connotations with youth, adolescents and adults who stutter.

The results also showed a three-factor solution reduced the 25 bi-polar adjective pairs to 17 bi-polar adjective pairs. The most prominent adjective pairs comprised Factor 1 labeled - Personality. The 3-, 4-, 5-, and 6-year-old child who stutters was labeled as significantly more guarded, nervous, shy, self-conscious, tense, withdrawn, afraid, insecure, quiet and more likely to avoid and be described as self-derogatory. This study confirms that the stuttering stereotype exists in children as early as 3 years of age. These findings support and expand the findings of Horsley and FitzGibbon (1987) which reported the stuttering stereotype in young children by SLPs, SLPs in training and teachers in the United Kingdom. We report the stuttering stereotype is held by university students for children as early as 3 years of age. Of equal concern is the fact that these ratings were made with no actual experiences (live or videotaped) but merely the words "He stutters." This suggests that the stuttering stereotype is extremely robust.

These negative attitudes toward pre-school children are particularly important in view of the fact that the majority of cases of stuttering begin during the preschool years, usually with an onset before 4 years of age (Bloodstein, 1995; Guitar, 2005; Shapiro, 1999; 
Venkatagiri, 2005). Currently, there is agreement in the field of stuttering that early intervention is critical to protect children from the negative effects of the chronic version of stuttering in adolescents and adults. It appears that if university students, who not only may become parents but significant others in the lives of children, hold negative attitudes, this may impact the child's view of their speech, their behavior, and their emerging social identity (Daniels \& Gabel, 2004).

According to many authors (Yairi \& Ambrose, 2004; Zebrowski, 1995) even though some normal disfluencies resemble stuttering, parents usually bring children to speech and language clinics because of a recent onset or increased frequency of stuttering behaviors (Yairi \& Ambrose, 2004). Recent evidence of randomized control trials of behavioral early intervention programs such as the Lidcombe Program support the need as well as the efficacy of child and parent programs (Lincoln \& Onslow, 1997; Onslow, Packman, \& Harrison, 2003). These programs focus on early intervention as a key to successful behavior management of fluency disorders. Negative stereotypes and prejudicial attitudes toward pre-school children who stutter may influence parental decisions for seeking professional help from SLPs. The threat of the stuttering stereotype may delay parents or significant key others in the child's environment from seeking help to avoid negative evaluation by pediatricians, pre-school teachers or even other family members. Our study underscores the concern for SLPs and advocates for pre-school children who stutter. Successful programs that assist in reducing or eradicating early stereotypical attitudes should be developed and evaluated by clinicians and researchers in the discipline.

The problem is not that the stuttering label helps to identify children who stutter, it is the "spread effect" (Wright, 1983) that creates a spoiled identity and may actually make treatment less desirable and more difficult. Interestingly, participants did not differ in their ratings of the child who stutters and the child who did not stutter on Factor 2 - labeled "sociability" and Factor 3 - labeled "speech." It was expected that negative attitudes would be found for speech behaviors. Instead participants did not rate children who stutter any less pleasant, cooperative, sensitive, friendly, talkative, or daring than children who did not stutter. White and Collins (1984) and Doody, Kalinowski, Armson, and Stuart (1993) hypothesized about the development of negative stereotypes reported in adults who stutter. They suggested the stuttering stereotype is based less on actual information, knowledge, or experience with PWS and based more on the evaluator's inference of what they think and feel during their own moments of normal disfluency. Contributing to the myths and fallacies about stuttering are social commentaries, books, movies, television, and even cartoons that show PWS demonstrating undesirable and negative attributes. This study is the first to document that the assignment of the negative stuttering stereotype is assigned at such an early age.

These results have implications for a new area in the social psychology literature dealing with stereotypes referred to as "stereotype threat" (Steele, 1997). Smith (2004) defines this phenomena as "a situational experience in which the individual feels vulnerable and pressured by the possibility of confirming or being judged by a stereotype" (p. 177). There is compelling evidence that the stereotype threat negatively impacts performance outcomes. Anxiety, evaluation apprehension, performance confidence, and self-handicapping traits are linked to stereotype threat and performance outcomes. It is 
possible if pre-school children who stutter begin to internalize some of the negative attributes of the stuttering stereotype and accompanying "threat," then even when fluency is facilitated or enhanced, negative attitudes and thoughts may remain. Further research needs to be done to examine these hypotheses.

We also reported a significant difference between the group of participants who knew or reported familiarity with PWS for Factor 1. This suggests that knowledge of PWS or stuttering resulted in higher positive ratings of the 3-, 4-, 5-, and 6-year-old children who stutter on 10 bi-polar adjectives. This is a positive finding and suggests that participants with some knowledge about stuttering or familiarity with PWS were less likely to assign negative attributes. This finding contradicts research with adults who stutter. Doody et al. (1993) surveyed 106 members in three small rural communities in Canada using a semantic differential scale to rate "a hypothetical adult male stutterer" and "a hypothetical adult male nonstutterer." Negative stereotypes of PWS were reported, although $85 \%$ of those surveyed stated knowing at least one person who stutters. Interestingly, $39 \%$ of the participants reported a family member was a PWS and still held the stuttering stereotype. They suggested that familiarity had no influence on reducing negative attitudes. Studies need to be conducted with similar stimuli and methods using both adults and child samples to make comparisons about the influence of knowing PWS on the stuttering stereotype.

More research is needed in this area to compare multiple age groups and genders on the stuttering stereotype. Studies could also be designed to determine the influence of knowledge about stuttering on stereotypes. Future studies need to also examine effective methods for reducing or eliminating the stuttering stereotype in all age groups. Studies need to determine if negative attitudes of children and adults who stutter lead to prejudicial thinking and discriminating behaviors. Multiple research paradigms examining stereotypical responses, self-handicapping behaviors, and stereotype threat should be researched in the area of fluency disorders for their relevance and application.

In addition, studies need to be conducted examining the stuttering stereotype using videotaped or live experiences with children who stutter. It may be that observing children who stutter reduces or negatively influences adjective ratings by participants. The advantage to providing a specific audio and visual stimulus is increased control over the participant's ratings. Researchers could control visibility, severity and other known factors that increase the likelihood of negative attitude formation and stereotyping.

\section{Appendix A. Vignette for 3-year-old child who stutters}

Kevin is a 3-year-old boy. He has a pet dog, Bruno, who he likes to run around outside with. Another thing Kevin likes to do is to swing as high as he can on the swings in the park. He also enjoys doing arts and crafts and likes creating pictures of superheroes. His favorite toy is his train set that he was given for his last birthday. Kevin stutters. Kevin loves to eat macaroni and cheese and anything chocolate. He does not like milk. Kevin's favorite dessert is chocolate ice cream sundaes with chocolate sprinkles. He lives at home with his father, mother, and older sister. 
Appendix B. Some examples of the format for the adjective pairs and instructions provided. Please circle the response you feel is most appropriate in regards to the child you just read about.

\begin{tabular}{|c|c|c|c|c|c|c|}
\hline \multicolumn{6}{|l|}{ Guarded } & \multirow{2}{*}{$\begin{array}{l}\text { Open } \\
\text { Very much }\end{array}$} \\
\hline Very much & Quite a bit & Slightly & Neutral & Slightly & Quite a bit & \\
\hline Nervous & & & & & & Calm \\
\hline Very much & Quite a bit & Slightly & Neutral & Slightly & Quite a bit & Very much \\
\hline Cooperative & & & & & & Uncooperative \\
\hline Very much & Quite a bit & Slightly & Neutral & Slightly & Quite a bit & Very much \\
\hline Friendly & & & & & & Unfriendly \\
\hline Very much & Quite a bit & Slightly & Neutral & Slightly & Quite a bit & Very much \\
\hline Pleasant & & & & & & Unpleasant \\
\hline Very much & Quite a bit & Slightly & Neutral & Slightly & Quite a bit & Very much \\
\hline Intelligent & & & & & & Dull \\
\hline Very much & Quite a bit & Slightly & Neutral & Slightly & Quite a bit & Very much \\
\hline Talkative & & & & & & Reticent \\
\hline Very much & Quite a bit & Slightly & Neutral & Slightly & Quite a bit & Very much \\
\hline
\end{tabular}

\section{CE Questions:}

1. Which of the following statement(s) is/are true according to previous research on perceptions and attitudes toward individuals who stutter?

a. Educators, administrators, speech language pathologists (SLPs), employers, peers, medical personnel, family members, and university students perceive PWS as more negative simply because of the presence of a communication disability.

b. This pervasive negative stereotype has implications for assessment, treatment, and quality of life for PWS.

c. Negative stereotypes and prejudices toward PWS may be formed early in childhood.

d. An integration of negative stereotypes in the social identity of the PWS may contribute to the "stigma" of stuttering.

e. All of the above are true.

2. Which of the following are listed as advantages in using vignette research methodology?

a. It allows for targeting specific kinds of questions for the researcher.

b. It decreases the use of pre-structured questions that often contain experimenter bias.

c. It allows for a depersonalization for the participant from specific personal experiences that might be viewed as threatening.

d. It allows for understanding the normative process without intrusive interviews.

e. All of the above.

3. Using a hypothetical vignette depicting either a three-, four-, five- or six-year-old with or without the statement "He stutters", we reported:

a. University students do not assign more negative ratings to the hypothetical construct based on the inclusion of the two-word sentence "He stutters." 
b. The factor labeled Personality showed significantly more negative ratings for three-, four-, five-, or six-year-old children based on the inclusion of the "He stutters" sentence.

c. The label "stutter" does not negatively influence participants' ratings.

d. There were no significant associations reported between raters' knowledge of stuttering and their familiarity with individuals who stutter.

e. All of the above are true.

4. A review of Figure 1 shows that the mean ratings of the vignette including "He stutters" were significantly higher for Adjective pairs 1-10.

a. True

5. Which of the following is NOT an important reason to research negative attitudes toward pre-school children?

a. The majority of cases of stuttering begin during the preschool years.

b. Negative stereotypes and prejudicial attitudes toward pre-school children who stutter may influence parental decisions for seeking professional help from SLPs.

c. The implications for a new area in the social psychology dealing with "stereotype threat" and the negative impact on performance outcomes.

d. Attitudes have no impact on individuals' perceptions and behaviors.

e. All of the above

\section{References}

Alexander, C. S., \& Becker, H. J. (1978). The use of vignettes in survey research. Public Opinion Quarterly, 42, 93-104.

Allard, E.R., \& Williams, D.F. (In press). Listeners' perceptions of speech and language disorders. Journal of Communication Disorders.

Bebout, L., \& Bradford, A. (1992). Cross-cultural attitudes toward speech disorders. Journal of Speech and Hearing Research, 35, 45-52.

Becker, J. A., Place, K., Tenzer, S., \& Frueh, B. C. (1991). Teachers' impressions of children varying in pragmatic skills. Journal of Applied Developmental Psychology, 12(4), 397-412.

Blood, G. W., Blood, I., Tellis, G., \& Gabel, R. (2001). Communication apprehension and self-perceived communication competence in adolescents who stutter. Journal of Fluency Disorders, 26, 1-19.

Bloodstein, O. (1995). A handbook on stuttering (5th ed.). San Diego, CA: Singular.

Corcoran, J. A., \& Stewart, M. (1998). Stories of stuttering: A qualitative analysis of interview narratives. Journal of Fluency Disorders, 23, 247-264.

Crichton-Smith, I. (2002). Communicating in the real world: Accounts from people who stammer. Journal of Fluency Disorders, 27, 333-352.

Crowe, T. A., \& Cooper, E. B. (1977). Parental attitudes and knowledge of stuttering. Journal of Communication Disorders, 10, 343-357.

Crowe, T., \& Walton, J. (1981). Teacher attitudes toward stuttering. Journal of Fluency Disorders, 6, $163-174$.

Daniels, D. E., \& Gabel, R. M. (2004). The impact of stuttering on identity construction. Topics in Language Disorders, 24(3), 200-216.

Davis, S., Howell, P., \& Cooke, F. (2002). Sociodynamic relationships between children who stutter and their nonstuttering classmates. Journal of Child Psychology and Psychiatry, 43(7), 939-947.

Doody, I., Kalinowski, J., Armson, J., \& Stuart, A. (1993). Stereotypes of stutterers and nonstutterers in three rural communities in Newfoundland. Journal of Fluency Disorders, 18, 363-373.

Dorsey, M., \& Guenther, R. K. (2000). Attitudes of professors and students toward college students who stutter. Journal of Fluency Disorders, 25, 77-83. 
Dresselhaus, T. R., Peabody, J. W., Luck, J., \& Bertenthal, D. (2004). An evaluation of vignettes for predicting variation in the quality of preventive care. Journal of General Internal Medicine, 19, 1013-1018.

Finch, J. (1987). The vignette technique in survey research. Sociology, 21, 105-114.

Gabel, R., Blood, G. W., Tellis, G., \& Althouse, M. (2004). Measuring role entrapment of people who stutter. Journal of Fluency Disorders, 29, 27-49.

Ginsberg, A. P. (2000). Shame, self-consciousness, and locus of control in people who stutter. The Journal of Genetic Psychology, 161, 389-399.

Guitar, B. (2005). Stuttering: An integrated approach to its nature and treatment (3rd ed.). Baltimore: Williams and Wilkins.

Ham, R. E. (1990). What is stuttering: Variations and stereotypes. Journal of Fluency Disorders, 15, $259-273$.

Hasket, M. E., Seott, S. S., Willoughby, M., Ahern, L., \& Nears, K. (2006). The parent opinion questionnaire and child vignettes for use with abusive parents: Assessment of psychometric properties. Journal of Family Violence, 21, 137-151.

Horsley, I. A., \& FitzGibbon, C. T. (1987). Stuttering children: Investigation of a stereotype. British Journal of Disorders of Communication, 22, 19-35.

Hughes, R., \& Huby, M. (2004). The construction and interpretation of vignettes in social research. Social Work and Social Sciences Review, 11, 36-51.

Hurst, M. I., \& Cooper, E. B. (1983). Employer attitudes toward stuttering. Journal of Fluency Disorders, 8, 1-12.

Jones, M., Onslow, M., Packman, A., Williams, S., Ormond, T., Schwarz, I., \& Gebski, V. (2005). Randomised controlled trial of the Lidcombe programme of early stuttering intervention. British Medical Journal 331(7518).

Kalinowski, J., Armson, J., Stuart, A., \& Lerman, J. W. (1993). Speech clinicians' and the general public's perceptions of self and stutterers. Journal of Speech-Language Pathology and Audiology, 17, 79-85.

Klein, J. F., \& Hood, S. B. (2004). The impact of stuttering on employment opportunities and job performance. Journal of Fluency Disorders, 29, 255-272.

Lass, N. J., Ruscello, D. M., Pannbacker, M. D., Schmitt, J. E., Riser, A. M., Musso, A. M., \& Lockhart, R. (1994). School administrators' perceptions of people who stutter. Language, Speech, and Hearing Services in Schools, 25, 90-93.

Lincoln, M., \& Onslow, M. (1997). Long-term outcome of an early intervention for stuttering. American Journal of Speech Language Pathology, 6, 51-58.

Murphy, B. (1999). A preliminary look at shame, guilt, and stuttering. In N. Bernstein \& C. Healey (Eds.), Stuttering research and practice: Bridging the gap (pp. 131-143). Mahwah, NJ: Erlbaum.

Onslow, M. (1996). Behavioral management of stuttering. San Diego, CA: Singular Publishing Group.

Onslow, M. (2003). Evidence based treatment of stuttering. V. Empowerment through evidence based treatment practices. Journal of Fluency Disorders, 28, 237-245.

Onslow, M., Packman, A., \& Harrison, E. (Eds.). (2003). The Lidcombe program of early stuttering intervention: A clinician's guide. Austin, TX: Pro-Ed.

Parker, E. H., Hubbard, J. A., Ramsden, S. R., Relyea, N., Dearling, K. F., Smithmyer, C. M., \& Schimmel, K. D. (2001). Children's use and knowledge of display rules for anger following hypothetical vignettes versus following live peer interaction. Social Development, 10, 528-557.

Rice, M., \& Kroll, R. (1997). Workplace experiences of people who stutter. Journal of Fluency Disorders, 22, 140.

Rutten, G. M., Harting, J., Rutten, S. T., Bekkering, G. E., \& Kremers, P. J. (2006). Measuring physiotherapists' guideline adherence by means of clinical vignettes: A validation study. Journal of Evaluation in Clinical Practice, 12, 491-500.

Schoenberg, N. E., \& Ravdal, H. (2000). Using vignettes in awareness and attitudinal research. International Journal of Social Research Methodology, 3, 63-74.

Shapiro, D. A. (1999). Stuttering intervention. Austin, TX: Pro-Ed.

Sheehan, J. G. (1970). Stuttering: Research and therapy. New York: Harper \& Row.

Smith, J. L. (2004). Understanding the process of stereotype threat: A review of mediational variables and new performance goal directions. Educational Psychology Review, 16(3), 177-206.

Steele, C. M. (1997). A threat in the air: How stereotypes share intellectual identity and performance.. American Psychologist, 52, 613-629.

Stolte, J. F. (1994). The context of sacrificing in vignette research. Journal of Social Psychology, 134, 727-733. 
Taylor, B. J. (2006). Factorial surveys: Using vignettes to study professional judgment. British Journal of Social Work, 36, 1187-1207.

Tabachnick, B. G., \& Fidell, L. S. (2006). Using multivariate statistics (5th ed.). Boston: Allyn and Bacon.

Tabachnick, G. G., \& Fidell, L. S. (2006). Experimental designs using ANOVA. Belmont, CA: Duxbury.

Turnbaugh, K. R., Guitar, B. E., \& Hoffman, P. R. (1979). Speech clinicians' attribution of personality traits as a function of stuttering severity. Journal of Speech and Hearing Research, 22, 37-45.

Van Borsel, J., Verniers, I., \& Bouvry, S. (1999). Public awareness of stuttering. Folia Phoniatrica et Logopaedica, 51, 124-132.

Van der Pas, S., van Tilburg, T., \& Knipscheer, K. C. (2005). Measuring older adults' filial responsibility expectations: Exploring the application of vignette technique and an item scale. Educational and Psychological Measurement, 65, 1026-1045.

Van Riper, C. (1982). The treatment of stuttering. Englewood Cliffs, NJ: Prentice-Hall.

Venkatagiri, H. S. (2005). Recent advances in the treatment of stuttering: A theoretical perspective. Journal of Communication Disorders, 38, 375-393.

Whaley, B. B., \& Parker, R. G. (2000). Expressing the experience of communicative disability: Metaphors of persons who stutter. Communication Reports, 13, 115-125.

White, P. A., \& Collins, S. R. (1984). Stereotype formation by inference: A possible explanation for the "stutterer" stereotype. Journal of Speech and Hearing Research, 27, 567-570.

Wilks, T. (2004). The use of vignettes in qualitative research into social work values. Qualitative Social Work, 3, 78-87.

Williams, D. F., \& Dietrich, S. (1996). Effects of speech and language disorders on raters' perceptions. Journal of Communication Disorders, 29, 1-12.

Williams, D. F., \& Dietrich, S. (2001). Perceptions of communicative disorders: Verification and specification of rater variables. Journal of Communication Disorders, 34, 355-366.

Wilson, J., \& While, A. E. (1998). Methodological issues surrounding the use of vignettes in qualitative research. Journal of Interprofessional Care, 12, 79-87.

Woods, C. L. (1978). Teachers' predictions of the social position and speaking competence of stuttering students. Language, Speech, and Hearing Services in the Schools, 6, 177-182.

Woods, C. L., \& Williams, D. E. (1971). Speech clinicians' conceptions of boys and men who stutter. Journal of Speech and Hearing Disorders, 36, 225-234.

Woods, C. L., \& Williams, D. E. (1976). Traits attributed to stuttering and normally fluent males. Journal of Speech and Hearing Research, 19, 267-278.

Wright, B. A. (1983). Physical disability: A psychosocial approach. New York: Harper \& Rowe.

Yairi, E., \& Williams, D. E. (1970). Speech clinicians' stereotypes of elementary-school boys who stutter. Journal of Communication Disorders, 3, 161-170.

Yairi, E., \& Ambrose, N. (2004). Early childhood stuttering. Austin, TX: Pro-Ed.

Yovetich, W. S., Leschied, A. W., \& Flicht, J. (2000). Self-esteem of school-age children who stutter. Journal of Fluency Disorders, 25, 143-153.

Zebrowski, P. M. (1995). The topography of beginning stuttering. Journal of Communication Disorders, 28(2), 75-91. 